\title{
Short communication: Effect of a citrus extract in lactating dairy cows
}

\author{
Y. Ying,${ }^{1}$ M. Niu, ${ }^{2}$ A. R. Clarke,${ }^{3}$ and K. J. Harvatine ${ }^{4}$ \\ Department of Animal Science, Pennsylvania State University, University Park 16802
}

\begin{abstract}
Dry matter intake is a main driver of energy balance in lactating dairy cows, and some plant extracts have been commercially fed to dairy cows to stimulate feed intake. Citrus extracts contain several bioactive components and have been shown to modify metabolism in other animal models. Our hypothesis was that a citrus extract would increase dry matter intake. Two experiments were conducted to determine the effect of a citrus extract on intake and milk production in lactating dairy cows. In experiment one, 11 early-lactation dairy cows (experiment 1; $77 \pm 15 \mathrm{~d}$ in milk, mean \pm standard deviation) were used in a switchback design, and in experiment two, 15 mid-lactation Holstein cows (experiment 2; $157 \pm 44 \mathrm{~d}$ in milk, mean \pm standard deviation) were used in a crossover design. In both experiments, treatments were control (no supplement) or a citrus extract $(4 \mathrm{~g} / \mathrm{d}$ in experiment 1 and $4.5 \mathrm{~g} / \mathrm{d}$ in experiment 2). Treatment periods were 21 and $14 \mathrm{~d}$ in experiment 1 and experiment 2, respectively, with the final $7 \mathrm{~d}$ used for sample and data collection. No effect was observed for treatment on dry matter intake, feeding behavior, milk yield, milk fat yield, milk protein yield, or milk composition in either experiment. Treatment also had no effect on milk trans fatty acid profile, but the extract increased total 16 carbon fatty acids 0.9 and 0.6 percentage points in experiment 1 and experiment 2, respectively. Plasma nonesterified fatty acids were decreased $6 \mathrm{~h}$ after feeding in both experiments (11.1 and $16.0 \mu \mathrm{Eq} / \mathrm{L}$ in experiment 1 and experiment 2 , respectively). Plasma insulin was increased $1 \mathrm{~h}$ before feeding compared with the control in experiment 1 (3.36 vs. $2.13 \mu \mathrm{IU} / \mathrm{mL}$ ) and tended to increase 1.79 units $1 \mathrm{~h}$ before feeding in experiment 2 . The citrus extract had no effect on feed intake or milk production at
\end{abstract}

Received October 30, 2016.

Accepted April 2, 2017.

${ }^{1}$ Current address: Department of Medicine, Penn Center for Pulmonary Biology, Penn Cardiovascular Institute, University of Pennsylvania, PA 19104.

${ }^{2}$ Current address: Department of Animal Science, University of California, Davis 95616.

${ }^{3}$ Current address: 2118 St., Rt. 168, Georgetown, PA 15043.

${ }^{4}$ Corresponding author: kjh182@psu.edu the dose investigated, but changed plasma insulin and nonesterified fatty acids, indicating some metabolic effects requiring further investigation.

Key words: citrus extract, feeding behavior, intake, insulin

\section{Short Communication}

Natural plant extracts may provide the opportunity to modify animal physiology to improve milk production and animal health. Citrus extracts contain several bioactive compounds, including alkaloids, flavonoids, tannins, phenols, and saponins, that have been investigated for their beneficial effect on several disease conditions including metabolic diseases in other model organisms (reviewed by $\mathrm{Li}$ et al., 2006; Favela-Hernandez et al., 2016). Citrus extracts contain polymethoxyflavones and hydroxylated polymethoxyflavones not found in other plants. The extracts have been proposed to have antimicrobial, antifungal, antiobesity, antiinflammatory, antistress, and antioxidant properties relevant to dairy cows. Additionally, citrus extracts have documented neurological effects in the central nervous system including antidepressant and sedative effects and effects on memory and learning (Roohbakhsh et al., 2014). Because intake is centrally regulated, citrus extracts may increase feed palatability and DMI of dairy cows, although little research has been conducted. Our objective was to test the effect of a citrus-based extract on milk production, feed intake, feeding behavior, and plasma metabolites in lactating dairy cows. Our hypothesis was that the extract would increase intake through either an increase in meal size or number of meals per day.

Two experiments were conducted using multiparous Holstein cows housed in a tie stall at the Pennsylvania State University Dairy Production Research and Teaching Center. All experimental procedures were approved by the Pennsylvania State University Institutional Animal Care and Use Committee. Eleven early lactation dairy cows were arranged in a switchback design with three 21-d periods in experiment 1 (experiment 1; $77 \pm 15$ DIM; mean \pm SD) and 15 mid-lactation dairy cows were arranged in a crossover design with two 14-d periods in experiment 2 (experiment 2; 157 
\pm 44 DIM; mean $\pm \mathrm{SD}$ ). Cows were fed the basal diet for $14 \mathrm{~d}$ before initiation of the experiment and there were no wash-out periods. Treatments were (1) control (no supplement) and (2) a citrus-based plant extract. The extract was fed at a target rate of $4 \mathrm{~g} / \mathrm{d}$ in experiment 1 and $4.5 \mathrm{~g} / \mathrm{d}$ in experiment 2 in a ground corn premix. Because peer-reviewed data are not available in cows, the dose was selected based on the feeding rate of similar supplements in the field. The dose was slightly increased in the second experiment, as a response was not observed in the first experiment and because of the high level of intake observed. Cows were fed once daily at $0900 \mathrm{~h}$ at $110 \%$ of expected intake, milked $2 \times / \mathrm{d}$ in a milking parlor, and received bST on $\mathrm{d} 1$ and 10 of each period in experiment 1 and on the first day of each period in experiment 2 (500 $\mathrm{mg}$ of sometribove zinc, Posilac, Elanco Animal Health, Greenfield, IN). Data were analyzed using the Fit Model procedure and the REML method of JMP (version 9.0.2, SAS Institute Inc., Cary, NC). Daily DMI was averaged over the last $3 \mathrm{~d}$ of each period, and milk yield and composition were averaged over the days observed. The model included the random effect of sequence, period, and cow nested in sequence and the fixed effect of treatment. The interaction of treatment and blood sampling time was tested and was significant for key variables, so data were separated by time point for analysis. Significant differences were declared at $P<0.05$ and tendencies declared at $0.05<P<0.10$.

Diet ingredients $(\sim 250 \mathrm{~g}$ of $\mathrm{DM})$ and individual orts ( $12.5 \%$ of orts) were sampled daily from on the last 3 $\mathrm{d}$ of each period and composited by period. All feed and orts were dried in a forced air oven at $65^{\circ} \mathrm{C}$. Feed samples were subsequently ground in a Wiley mill (A. H. Thomas Co., Philadelphia, PA) using a 1-mm screen and analyzed by wet chemistry procedures $[\mathrm{CP}$ (AOAC International, 2000) by amylase-treated NDF (Van Soest et al., 1991) by Cumberland Valley Analytical Services (Maugansville, MD; analytical methods are available at http://www.foragelab.com/Resources/ Lab-Procedures]. The corn-silage- and alfalfa-haylagebased diets contained 32.0 and $33.4 \% \mathrm{NDF}$ and 29.4 and $28.1 \%$ starch in experiment 1 and experiment 2, respectively (Supplemental Table S1; https://doi. org/10.3168/jds.2016-12233).

Dry matter intake was not modified by the extract in the first experiment, which used earlier lactation cows $(77 \pm 15$ DIM; mean \pm SD) that had higher milk yield $(53 \mathrm{~kg} / \mathrm{d})$ and DMI $(33.0 \mathrm{~kg} / \mathrm{d}$; Table 1). It is possible that physical fill limited intake in this situation. Intake is regulated through integration of multiple signals in the brain and a stimulatory signal would not be expected to overcome physical fill limitations (Allen, 1996). Therefore, the second experiment was conducted in a separate group of mid-lactation cows with more moderate milk production and DMI $(37 \mathrm{~kg} / \mathrm{d}$ of milk and $27.5 \mathrm{~kg}$ of DMI). However, the extract also had no effect on DMI in the second experiment (Table 1). Feeding behavior was observed in a feed intake observation system with hanging feed tubes suspended from an electronic load cell wired into a data acquisition system (Niu et al., 2017). Extract had no effect on meal number, length, size, or interval or time spent eating (Table 1). The extract had a tendency to increase eating rate in experiment 2 (98 vs. $89 \mathrm{~g} / \mathrm{min} ; P=0.09)$. Also, no apparent differences were observed in the pattern of feed intake over the day (Supplemental Figure S1; https://doi.org/10.3168/jds.2016-12233). The extract has the potential to act through an olfactory mechanism (Nagai et al., 2014). Treatment sequence was randomly assigned to stall in both experiments and cows were housed next to each other in the barn. Control cows were therefore exposed to the olfactory characteristics of feed in their vicinity. Additionally, cows were housed in tie stalls, and motivation for feeding behavior may be different in tie stalls compared with free stalls and the effect of the extract on feeding behavior in free stall barns should be investigated. Based on the current experiments, consumption of the extract had no effect on intake and feeding behavior of healthy lactating cows.

Milk yield determined by an integrated milk meter and milk composition at the 4 consecutive milkings on the last $2 \mathrm{~d}$ of each period was determined by infrared spectroscopy (AOAC International, 2000; method 972.160, Dairy One Lab, State College, PA). No effect was observed of the extract on milk yield or milk composition in either experiment. An additional milk sample was collected at each milking on the last day of each period, and was analyzed for fatty acid (FA) profile as described by (Rico and Harvatine, 2013). No effect was observed on milk trans FA profile, indicating no change in ruminal biohydrogenation pathways or capacity (Table 2; Supplemental Table S2; https:// doi.org/10.3168/jds.2016-12233). The extract increased total 16 carbon FA 0.9 and 0.6 percentage units in experiment 1 and experiment 2, respectively, due to an increase in C16:0, but had no effect on de novo or preformed FA concentration (Table 2). The FA profile of the extract was not analyzed, but this increase is not expected to be due to palmitic in the product because of the low dose fed (4 and $4.5 \mathrm{~g} / \mathrm{d}$ ). Hydroxylated polymethoxyflavones from Citrus sinensis reduced fat synthesis in 3T3-L1 adipocytes and decreased adiposity and fatty liver in C57BL/6 mice fed a high-fat diet (Lai et al., 2013). Increased C16:0 in the current experiment may indicate modification of activity of FA synthase or thioesterase II by bioactive compounds in the extract (Palmquist, 2006). 
Table 1. Effect of a citrus-based extract on feed intake and feeding behavior in lactating dairy cows

\begin{tabular}{|c|c|c|c|c|c|c|c|c|}
\hline \multirow{2}{*}{ Item } & \multicolumn{4}{|c|}{ Experiment $1^{1}$} & \multicolumn{4}{|c|}{ Experiment $2^{1}$} \\
\hline & \multicolumn{2}{|c|}{ Means } & $\mathrm{SE}$ & $P$-value & \multicolumn{2}{|c|}{ Means } & $\mathrm{SE}$ & $P$-value \\
\hline $\begin{array}{l}\text { DMI, kg/d } \\
\text { Meal }\end{array}$ & 33.1 & 33.0 & 0.91 & 0.91 & 27.3 & 27.5 & 1.14 & 0.63 \\
\hline Frequency, no./d & 11.4 & 11.3 & 0.72 & 0.84 & 10.8 & 10.8 & 0.78 & 0.96 \\
\hline Intermeal, min & 87.6 & 89.1 & 5.82 & 0.76 & 100.8 & 95.3 & 10.7 & 0.24 \\
\hline \multicolumn{9}{|l|}{ Eating } \\
\hline Time, $\min / \mathrm{d}$ & 246 & 241 & 9.9 & 0.46 & 287 & 288 & 13.1 & 0.97 \\
\hline Rate, g/min & 110 & 120 & 10 & 0.23 & 98 & 89 & 7 & 0.09 \\
\hline
\end{tabular}

${ }^{1}$ Treatment was a citrus-based extract fed at a target rate of $4 \mathrm{~g} / \mathrm{d}$ in experiment 1 and $4.5 \mathrm{~g} / \mathrm{d}$ in experiment 2.

Blood samples were collected $1 \mathrm{~h}$ before and $6 \mathrm{~h}$ after feeding on the last day of each period to represent near the lowest and highest points of the day for nutrient absorption. Blood was collected from the tail vein using potassium EDTA vacuum tubes and plasma was harvested and analyzed for insulin [Coat-a-count insulin kit (TKIN5), Siemens Healthcare Diagnostics, Los Angeles, CA], glucose (PGO Enzyme procedure no. P 7119, Sigma-Aldrich; Raabo and Terkildsen, 1960), and nonesterified fatty acids [NEFA; Wako HR Series NEFA-HR(2) kit, Wako Chemicals USA Inc., Richmond, VA, as modified by Ballou et al. (2009)]. Plasma glucose concentration was not changed by treatment at either time point (Table 3). Plasma NEFA was not modified before feeding, but was decreased by the extract $6 \mathrm{~h}$ after feeding in both experiments (11.1 and $16.0 \mu \mathrm{Eq} / \mathrm{L}$ in experiment 1 and experiment 2, respectively). Hydroxylated polymethoxyflavones from Citrus sinensis reduced plasma triglycerides in $\mathrm{C} 57 \mathrm{BL} / 6$ mice fed a high-fat diet (Lai et al., 2013). Plasma insulin was increased $1 \mathrm{~h}$ before feeding compared with the control in experiment $1(0.86 \mu \mathrm{IU} / \mathrm{mL})$, but tended to be decreased 1.79 units before feeding in experiment 2 $(P=0.08)$. The extract had no effect on plasma insulin after feeding, although insulin was numerically 3.07 units higher than control after feeding in experiment $2(P=0.11)$. The reason for this differential effect on insulin is not clear. Cows in experiment 1 had earlier lactation and were higher producing than experiment 2 . The changes in plasma NEFA and insulin may be due to modification of insulin signaling and adipose tissue lipolysis, which may interact with physiological state, but will require mechanistic investigation of intracellular adipose tissue signaling or response to glucose challenge. The ability of the extract to modify insulin and NEFA open potential application during the transition

Table 2. Effect of a citrus-based extract on milk production and composition and milk fatty acid (FA) profile in lactating dairy cows

\begin{tabular}{|c|c|c|c|c|c|c|c|c|}
\hline \multirow{2}{*}{ Item } & \multicolumn{4}{|c|}{ Experiment $1^{1}$} & \multicolumn{4}{|c|}{ Experiment $2^{1}$} \\
\hline & \multicolumn{2}{|c|}{ Means } & $\mathrm{SE}$ & $P$-value & \multicolumn{2}{|c|}{ Means } & $\mathrm{SE}$ & $P$-value \\
\hline \multicolumn{9}{|l|}{ Yield, $\mathrm{kg} / \mathrm{d}$} \\
\hline Milk & 53.1 & 53.8 & 1.91 & 0.60 & 37.9 & 37.4 & 0.90 & 0.57 \\
\hline Milk fat & 1.84 & 1.85 & 0.10 & 0.81 & 1.46 & 1.44 & 0.10 & 0.60 \\
\hline Fat & 3.48 & 3.47 & 0.16 & 0.84 & 3.86 & 3.87 & 0.20 & 0.87 \\
\hline Protein & 3.09 & 3.10 & 0.06 & 0.56 & 3.32 & 3.30 & 0.05 & 0.46 \\
\hline \multicolumn{9}{|c|}{ Selected milk FA, ${ }^{2} \mathrm{~g} / 100 \mathrm{~g}$ of FA } \\
\hline trans-10 C18:1 & 0.54 & 0.56 & 0.05 & 0.42 & 0.54 & 0.53 & 0.16 & 0.61 \\
\hline trans-11 C18:1 & 1.07 & 1.07 & 0.07 & 0.90 & 0.94 & 0.96 & 0.05 & 0.54 \\
\hline$\Sigma<16 \mathrm{C}$ & 29.6 & 29.9 & 0.44 & 0.40 & 29.3 & 29.2 & 0.83 & 0.76 \\
\hline$\Sigma 16 \mathrm{C}$ & 27.5 & 26.6 & 0.70 & 0.02 & 27.2 & 26.6 & 0.86 & 0.03 \\
\hline
\end{tabular}

${ }^{1}$ Treatment was a citrus-based extract fed at a target rate of $4 \mathrm{~g} / \mathrm{d}$ in experiment 1 and $4.5 \mathrm{~g} / \mathrm{d}$ in experiment 2 .

${ }^{2}$ Fatty acids $<16$ carbons originate from mammary de novo synthesis, FA $>16$ carbons originate from extraction from plasma, and 16 carbon FA originate from both sources. 
Table 3. Effect of a citrus-based extract on plasma metabolites $1 \mathrm{~h}$ before and $6 \mathrm{~h}$ after feeding in lactating cows

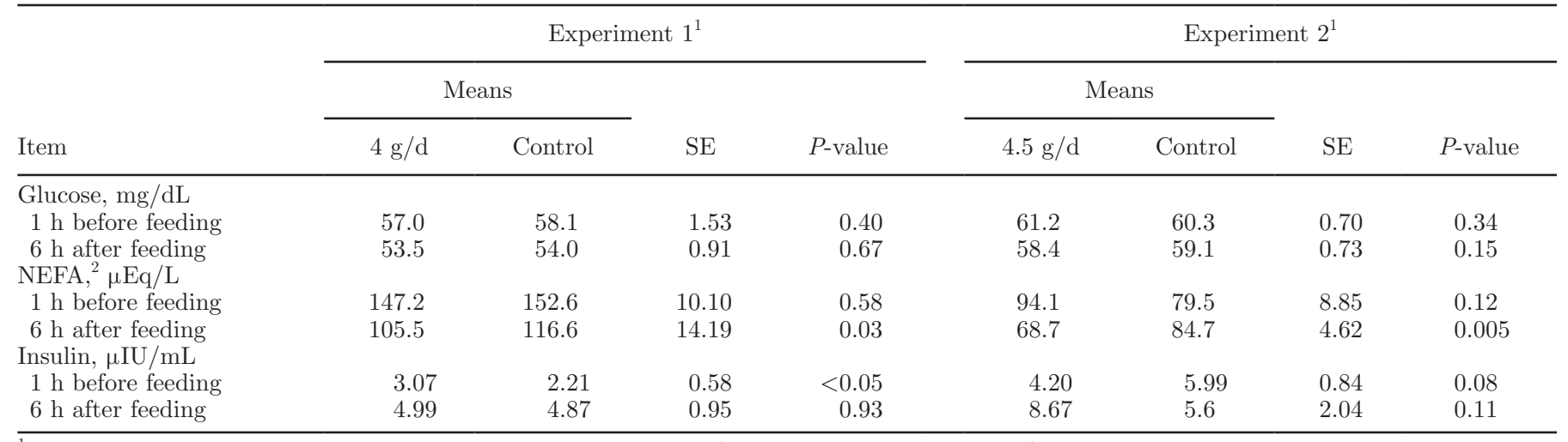

${ }^{1}$ Treatment was a citrus-based extract fed at a target rate of $4 \mathrm{~g} / \mathrm{d}$ in experiment 1 and $4.5 \mathrm{~g} / \mathrm{d}$ in experiment 2.

${ }^{2} \mathrm{NEFA}=$ nonesterified fatty acids.

period and the potential to modify nutrient partitioning during lactation as insulin is a key player in adipose regulation, although these were outside the scope of the current work and require specialized experiments to specifically investigate.

In conclusion, the citrus extract did not increase DMI or change meal size or number in either experiment and failed to support our hypothesis at the dose investigated ( 4 and $4.5 \mathrm{~g} / \mathrm{d}$ ). Higher doses may be effective, but will require additional investigation. However, the small, but repeatable, decrease in milk 16 carbon FA concentration, decrease in NEFA after feeding, and modification of insulin demonstrate that the extract had some bioactive metabolic properties.

\section{ACKNOWLEDGMENTS}

The authors gratefully acknowledge the technical assistance of D. E. Rico and L. Whitney Rottman (Penn State University, University Park, PA). Gratitude is also expressed to the Pennsylvania State University Dairy Cattle Research and Education Center (University Park). The authors thank Walter Kennett (Kennstock Diary Nutrition, Pottsville, PA) for insightful discussion.

\section{REFERENCES}

Allen, M. S. 1996. Physical constraints on voluntary intake of forages by ruminants. J. Anim. Sci. 74:3063-3075.

AOAC International. 2000. Official Methods of Analysis. 17th ed. AOAC Int., Gaithersburg, MD.
Ballou, M. A., R. C. Gomes, S. O. Juchem, and E. J. DePeters. 2009. Effects of dietary supplemental fish oil during the peripartum period on blood metabolites and hepatic fatty acid compositions and total triacylglycerol concentrations of multiparous Holstein cows. J. Dairy Sci. 92:657-669.

Favela-Hernandez, J. M., O. Gonzalez-Santiago, M. A. Ramirez-Cabrera, P. C. Esquivel-Ferrino, and R. Camacho-Corona Mdel. 2016. Chemistry and pharmacology of Citrus sinensis. Molecules 21:247.

Lai, C. S., M. H. Ho, M. L. Tsai, S. Li, V. Badmaev, C. T. Ho, and M. H. Pan. 2013. Suppression of adipogenesis and obesity in highfat induced mouse model by hydroxylated polymethoxyflavones. J. Agric. Food Chem. 61:10320-10328.

Li, S., C. Y. Lo, and C. T. Ho. 2006. Hydroxylated polymethoxyflavones and methylated flavonoids in sweet orange (Citrus sinensis) peel. J. Agric. Food Chem. 54:4176-4185.

Nagai, K., A. Niijima, Y. Horii, J. Shen, and M. Tanida. 2014. Olfactory stimulatory with grapefruit and lavender oils change autonomic nerve activity and physiological function. Auton. Neurosci. 185:29-35.

Niu, M., Y. Ying, P. A. Bartell, and K. J. Harvatine. 2017. The effects of feeding rations that differ in fiber and fermentable starch within a day on milk production and the daily rhythm of feed intake and plasma hormones and metabolites in dairy cows. J. Dairy Sci. 100:187-198.

Palmquist, D. L. 2006. Milk fat: Origin of fatty acids and influence of nutritional factors thereon. Pages 43-92 in Advanced Dairy Chemistry. Vol. 2: Lipids. 3rd ed. Springer, New York, NY.

Raabo, E., and T. C. Terkildsen. 1960. On the enzymatic determination of blood glucose. Scand. J. Clin. Lab. Invest. 12:402-407.

Rico, D. E., and K. J. Harvatine. 2013. Induction of and recovery from milk fat depression occurs progressively in dairy cows switched between diets that differ in fiber and oil concentration. J. Dairy Sci. 96:6621-6630.

Roohbakhsh, A., H. Parhiz, F. Soltani, R. Rezaee, and M. Iranshahi. 2014. Neuropharmacological properties and pharmacokinetics of the citrus flavonoids hesperidin and hesperetin-A mini-review. Life Sci. 113:1-6.

Van Soest, P. J., J. B. Robertson, and B. A. Lewis. 1991. Methods for dietary fiber, neutral detergent fiber, and nonstarch polysaccharides in relation to animal nutrition. J. Dairy Sci. 74:3583-3597. 